\title{
An Alternative Framing of Organ Donation Registration: The Collective Donor Behavioral Model
}

Emma Tinning, The University of Melbourne, Level 4, 207-221 Bouverie St., Victoria 3010. emma.tinning@unimelb.edu.au, discipline- Public Health.

Timothy C. Bednall, Swinburne Business School, BA1005, John Street, Victoria, 3122, Australia. tbednall@swin.edu.au, discipline- Management

Dr Liliana L. Bove*, The University of Melbourne, Level 10, 198 Berkeley Street, Victoria 3010, Australia.1bove@unimelb.edu.au, discipline- Marketing

Helen Jordan, The University of Melbourne, Level 4, 448B, 207-221 Bouverie St., Victoria 3010. h.jordan@unimelb.edu.au, discipline -Public health

* Corresponding author

\section{Authors Note}

This research was supported by an Australian Government Research Training Program

Scholarship

\section{Keywords}

organ donation registration, commitment, trust, theory of planned behavior, social exchange theory 


\begin{abstract}
Notwithstanding the prevalent use of donor registration prediction models underpinned by the theory of planned behaviour (TPB), registration behavior continues to remain low. A collective donor behavior (CDB) model underpinned by social exchange theory is introduced and its predictive ability is tested against a baseline TPB model using an online survey of adults $(n=1055)$. Individuals who indicated they were not registered donors were contacted three months later to track their registration status. The CDB model was found to explain $45 \%$ of variance in registration intentions which was comparable in performance to TPB. Normative commitment was found to be strongly associated with registration intentions, and both institutional trust and trust in others fostered this commitment. The CDB model provides different insights on how to increase donor registration intentions. Namely, interventions need to facilitate individual positive experiences with institutions such as hospitals and strengthen social inclusion perceptions.
\end{abstract}

\title{
Introduction
}

Globally, there is a disparity between needed and available organs. In the US, an estimated 20 people die each day while awaiting a transplant (HRSA, 2019) despite increases in the number of (deceased) donors and organs authorized for recovery (Israni et al., 2019). With many nations using "opt in" registration systems that require family consent, much of the eligible population are unregistered despite widespread supportive attitudes (O'Carroll et al., 2016; Siegel et al., 2014). For example, although $95 \%$ of Americans are in favor of being a donor, only $58 \%$ are 
registered (Donate Life America, 2019). These low rates are surprising, given continued health promotions (Siegel et al., 2008), decades of research on registration behavior, and the use of targeted interventions (Jones et al., 2017).

The Theory of Planned Behaviour (TPB) (Fishbein \& Ajzen, 2010) is frequently used to explain donation behavior (see Farsides, 2010; Hyde et al., 2013; Bresnahan et al., 2007; Rocheleau, 2013). It suggests that registrations are driven by positive attitudes towards organ donation (based on its apparent benefits and costs), perceiving behavioral control (the perceived ease of registering) and subjective norms (the perceived pressure from others to register). The TPB underpins many of the predictive models of organ donor registration behavior, for example, Horton and Horton's (1991) Organ Donor Model, The Organ Donor Willingness Model (Kopfman \& Smith, 1996), and The Organ Donation Model (Morgan \& Miller, 2002). A metaanalysis of 24 publications using variables underpinned by the TPB concluded that registered organ donors differed from non-donors by their level of positive attitude, altruism, social influence, communication about organ donation with their families, and lower fear regarding organ donation upon death (Nijkamp et al., 2008).

Although the TPB focuses on the individuals' beliefs and the opinions of others, it does not consider the individuals' embeddedness within society, nor the institutions with which they interact (Levi, 1991; Rothstein, 2000, 2001). These issues are important in the context of public goods such as donated organs, as contributions represent a social contract between individuals, governments, and other society members (Levi, 1991). When contemplating whether to contribute to public goods, donors face two social dilemmas (Rothstein, 2001). These include the 
need to trust institutions charged with delivering public goods, and the need to trust other society members who may consume but not contribute to public goods.

Drawing on Levi's and Rothstein's accounts of participation in public goods and social exchange theory's (Blau, 1964) explanation of prosocial behavior (Foddy \& Dawes, 2008; Lawler et al., 2001), we develop a model of Collective Donor Behavior (CDB). Social exchange theory sees deceased donation as an interdependent behavior (Etzioni, 2003; Schweda \& Schicktanz, 2009; Shaw et al., 2012), with organ donor registration part of a social system (Etzioni, 2003) underpinned by reciprocal obligations (Siegal \& Bonnie, 2006) or generalised exchanges among society members. Generalised exchanges involve diffuse obligations between society members, as opposed to tit-for-tat transactions (Blau, 1964). Less about individual transactions, generalised exchanges are "systems of social solidarity" (Giesler, 2006); the glue that holds societies together.

The CDB model acknowledges the institutional and social context of organ donation and the interdependence between the donation and transplant systems (Healy, 2004). The CDB model posits that perceptions of justice and social inclusion respectively are key antecedents of trust in institutions and other people. These objects of trust are mechanisms by which individuals' obligation is deepened (operationalized as normative commitment) and their attachment to the (organ donation) cause is strengthened (operationalized as affective commitment). Both types of commitment increase an individual's propensity to register for organ donation.

The aim of this study is to compare the ability of the CDB and TPB models in predicting donor registration behavior. This is important as the CDB model offers a different route to donor 
registration behavior. Namely, the CDB model focuses on developing commitment, which influences behavior independently of other motives and target-relevant attitudes (Meyer \& Herscovitch, 2001). Therefore, we make a number of contributions to theory and practice. First, we extend the use of social exchange theory to explain organ registration behavior. This differs from traditional TPB approaches which focus on developing favorable attitudes towards organ donation. Instead, the CDB model implies a focus on developing obligation, and it illustrates how to achieve collective cooperation.

\section{The Collective Donor Behavior (CDB) Framework}

Trust is one of the most significant concepts in theories of both collective behavior and social exchange (Molm et al., 2000). Trust in the donation process has been identified as a critical factor in securing an adequate supply of organs (Brown, 2018). Trust is future-oriented and is defined as "confident, positive expectations about the words, actions, and decisions of another in situations entailing risk" (Colquitt et al., 2012, p.1). While trust in social exchange and social dilemma theories generally relate to an assessment of the behavior of others (Yamagishi \& Cook, 1993), the CDB model includes two objects of trust: trust in others and institutional trust. Trust in others relates to trust between group members, which facilitates cooperation (Brewer, 2008). Foddy and Dawes (2008) describe this kind of trust as "social assurance" (p.57). Trust in others, also referred to as depersonalised trust (Brewer, 2008), is founded on two assumptions: 1) perceptions that one is part of a group and that others recognize and accept one as a group member, and 2) that group members will behave fairly towards other group members. In the CDB model, trust in others captures the trust between society members in relation to organ 
donation and transplantation, that is, the belief that other society members are also willing to register as donors and not free ride the system.

Institutional trust relates to perceptions regarding the dependability of the institutions underpinning the donation and transplant systems. Economic and social exchanges are embedded in cultural and institutional structures that provide constraints on and incentives for behavior (Granovetter, 1985). The provision of public goods is almost inevitably mediated through institutions (Mau, 2004), and studies consistently indicate that institutional mistrust (e.g., hospitals) is a barrier to donation (Almassi, 2014; Siminoff \& Arnold, 1999). This institutional mistrust includes fears that physicians may withhold or prematurely withdraw life-saving treatment for registered donors (Brown, 2018; Goldberg et al., 2013), that individuals will be subjected to invasive, non-consensual interventions for organ optimisation (Brown, 2018), and perceptions that some groups, such as the rich and famous, get preferential access to organs (Boulware et al., 2006).

Trust in organ donation and transplant systems is influenced by perceptions of the health system overall (Siminoff et al., 2006). This may be due to the difficulty in judging the trustworthiness of specific organ donation and transplant programs, which have been characterized as offering "little openness and transparency" (Brown, 2018, p.145).

\section{Hypotheses}

The conceptual framework of the CDB model with its hypothesized relationships is shown in Figure 1.

Insert Figure 1 about here 
Justice perceptions and institutional trust. Fairness perceptions have been shown to influence institutional trust and collective behaviors in relationships in the workplace (Colquitt et al., 2012; Konovsky \& Pugh, 1994), community policing (Bradford, 2014), and interactions with government bodies (McComas et al., 2007). Fairness perceptions with respect to the CDB model relate to three forms of justice: (1) distributive, the perceived fairness of decision outcomes, (2) procedural, the perceived fairness of decision-making processes, and (3) interactional, the perceived fairness of the one-to-one interpersonal treatment received as procedures are enacted (Colquitt et al., 2012).

First, distributive justice is reflected by perceptions of equity in decision outcomes. Perceptions of inequity in decisions lead to doubt about an institution's competence, reliability and professionalism, all components of trust (Colquitt et al., 2012). Second, individuals pay close attention to those aspects of procedures that enable them to evaluate decision-making processes, as this facilitates attributions regarding outcomes and whether those outcomes are deserved (Blader \& Tyler, 2003). As such, procedural justice is fostered when authorities provide the individual with the opportunity to input into key decisions, and when authorities utilize procedures that are perceived as "consistent, accurate, unbiased, correctable, representative of the group concerns, and ethical" (Colquitt et al., 2012, p. 3). Third, interpersonal justice is fostered when authorities treat individuals with respect and dignity (Colquitt et al., 2012). When interpersonal justice is perceived to be low this reflects a lack of professionalism, signalling low trust of institutions (Blader \& Tyler, 2003; Colquitt et al., 2012). 
Few individuals are likely to have prior interactions with organ donation and transplantation institutions; however, most adults have had some interaction with hospitals. As there is a halo effect between health institutions and organ donation and transplantation institutions (Irving et al., 2012), perceptions of fairness in prior interactions in hospitals are expected to translate to organ donation and transplant system institutional trust. Thus:

Hypothesis 1 (H1): Distributive (a), procedural (b) and interactional (c) justice perceptions within the hospital system are positively associated with institutional trust in the organ donation and transplant system.

Social inclusion and trust in others. Inclusion is identified as a primary human need (Sheldon \& Gunz, 2009), and inclusion in a community or group facilitates a shared interest in behaving collectively, as group members can be trusted (Yamagishi \& Kiyonari, 2000). Inclusion in a group increases cooperation between members (Hillebrandt et al., 2011) and willingness to participate in prosocial behaviors (Twenge et al., 2007). Conversely, social exclusion negatively impacts attitudes towards deceased donation; those who feel alienated from society are less inclined to donate (Morgan, Mayblin \& Jones, 2008).

In the case of donor registration, as with many public goods, the group extends to the society in which organ donation and transplantation systems operate; such that:

Hypothesis 2 (H2): Social inclusion is positively associated with trust in others.

Evidence suggests that institutional trust can facilitate trust between society members by encouraging fair behavior in communities (Levi, 1998; Rothstein, 2000). Institutions help set the tone of a society; where institutions are perceived to be corrupt and ineffective, trust between 
society members is likely to be low. Conversely, where institutions are perceived as fair and just, people have some basis to trust others (Rothstein, 2000). Hence:

Hypothesis 3 (H3): Institutional trust is positively associated with trust in others.

Trust and commitment. Commitment is a psychological attachment to a goal (Meyer et al., 2002) and in social relationships, demonstrations of trust are shown to build solidarity and commitment (Molm, 2010). Meyer \& Allen (1991) identify three types of commitment within exchange relationships - affective, normative, and continuance. With respect to prosocial behavior these three forms of commitment can be understood as (1) wanting to act, (2) feeling obliged to act, and (3) needing to act, respectively.

In the case of registering as a donor, affective commitment may manifest itself in feelings of emotional attachment (Meyer \& Herscovitch, 2001) to the cause of organ donation. For example, donation promotion campaigns that utilise narratives of real organ donors and transplant recipients, attempt to encourage registration by fostering affective commitment (Kopfman et al., 2009). Normative commitment is described as "the mind-set of obligation" (Meyer \& Herscovitch 2001, p.317) and promotional appeals tapping into this commonly express deceased donation as a moral obligation (Savulescu, 2003). For example, Etzioni (2003) argues that the preferences of non-donors can be changed through "moral persuasion, community appreciation of good conduct, and gentle chiding of those who do not do what is considered right” (p.5). Continuance commitment which is characterized by a cost-avoidance mindset (Meyer \& Herscovitch, 2001) may be evident in donation and transplant systems such as in Israel and Singapore that employ the threat of sanctions to encourage donation (Burkell, Chandler \& Shemie, 2013). However, continuance commitment is unlikely to be an outcome of either trust in 
others or institutional trust, as it is founded on utilitarian assessments of the costs and benefits of participating versus not participating. Equally, as a one-off behavior, it is unlikely that registered donors will withdraw their consent to donate. Consequently, as continuance commitment is not relevant in this context, it is omitted. This is supported by Meyer and Herscovitch (2001) who propose that continuance commitment either correlates negatively or does not correlate with discretionary behavior.

Within the prosocial literature, trust is shown to be a key antecedent to commitment to donating (Sargeant \& Lee, 2004). Institutional trust fosters normative commitment by creating a relationship of mutual obligation or a norm of reciprocity (Konovsky \& Pugh, 1994). Relatedly, institutional trust fosters affective commitment by congruent values between the individual and the institution (Liou \& Nyhan, 1994). Thus:

Hypothesis 4a (H4a): Institutional trust is positively associated with normative commitment to organ donation registration.

Hypothesis $4 \mathbf{b}(\mathbf{H} 4 \mathbf{b})$ : Institutional trust is positively associated with affective commitment to organ donation registration.

Similar to institutional trust, trust in others promotes normative commitment because it reduces uncertainty about others' reciprocation while fostering a sense of obligation (Konovsky \& Pugh, 1994). When there is trust in others, individuals are more likely to discharge their obligation to register, in part because they feel such efforts will be reciprocated down the line and thus obligations will balance out in the long term (Colquitt et al., 2012). Further, trust in others facilitates affective commitment to the organ donation cause because it encourages 
affective bonds within the group and commitments to further the group's interests (Lawler et al., 2001). Thus:

Hypothesis 5a (H5a): Trust in others is positively associated with normative commitment to organ donation registration.

Hypothesis 5b (H5b): Trust in others is positively associated with affective commitment to organ donation registration.

Commitment and donor registration intentions. Commitment is shown to be reliable predictor of discretionary behaviors (Colquitt et al., 2012) such as prosocial acts (Meyer \& Allen, 1991; Sargeant \& Lee, 2004), including blood donation (Bednall et al., 2013). Normative commitment and its felt obligation, and affective commitment and its felt passion, are mindset forces that bind the individual to action that benefits the collective (Meyer \& Herscovitch, 2001). Hence:

Hypothesis 6a (H6a): Normative commitment to organ donation registration is positively associated with organ donor registration intentions.

Hypothesis 6b (H6b): Affective commitment to organ donation registration is positively associated with organ donor registration intentions.

\section{Method}

\section{Participants}

Ethics approval for the study was obtained by The University of Melbourne ID1545343.1. Through a market research company, a sample of 1055 adults over 18 was recruited, using randomized sampling representative of the Australian adult population (regarding gender, age 
and location) using a voluntary online panel. The typical respondent was male (55\%), 35-44 years $(19.6 \%)$ with a bachelor degree $(23.8 \%)$ of no religion $(40 \%)$. Following the removal of cases where respondents uniformly selected the "neutral" scale or indicated they were unsure of their registration status, a final sample $n=887$ remained of which $514(58 \%)$ indicated they had never registered as organ donors. An expressed willingness to register may not translate to actual behavior as a proxy for actual registration behaviour (Katz et al., 2019). Therefore, we resurveyed all non-registered respondents at time 1 three months later to determine whether they had actually registered. Of the 272 respondents who replied (53\%), we recorded each participant as having registered if they: (1) indicated they had since registered $(n=12)$, or (2) clicked and stayed for three minutes or more on the optional registration link of the Australian Organ Donor website provided before the end of the survey and subsequently confirmed they had registered $(n=21)$. If neither of these conditions were met, we recorded them as having not registered.

\section{Measures}

All measures in the study were derived from established scales and where needed were adapted to the context. All self-report items were evaluated using 1 (strongly disagree) to 7 (strongly agree) Likert scales. Justice perceptions were adapted from Colquitt (2001). Social inclusion items were adapted from the General Belongingness Scale (Malone et al., 2012). Institutional trust in organ donation and transplant systems was measured using items from Robinson et al. (2012) and Siminoff, Burant \& Ibrahim (2006). Trust in others was adapted from Molm, Collett \& Schaefer (2007), whilst measures for affective and normative commitment were adapted from Allen and Meyer (1990). 
Donor registration intention is the most proximate factor underlying registration behavior (Armitage \& Conner, 2001), and consistent with Gerend and Shepherd's (2012) recommendation, as the aim of this study is to compare the TPB with $\mathrm{CDB}$, it is appropriate to "level the playing field" (p.9). Thus the choice was to either include intentions in the comparison model or exclude it from the TPB. The former approach was decided upon and intentions to register was measured using three items from Newton et al. (2013). Donor registration status was self-reported using a single item, “Are you a registered organ donor?" Last, measures for TPB constructs were adopted from Newton et al. (2013).

\section{Control Variables}

The study controlled for three factors known to affect organ donation behavior: organ donation knowledge, experience with organ donation or transplantation, and religiosity (Falomir-Pichastor et al., 2013). Knowledge was measured as the sum of the correct answers in Sander and Miller's (2005) 11-item scale. Experience-assessed as a person's acquaintance with someone who had donated or received an organ — was measured using 4-items of Rumsey, Hurford and Cole's (2003) scale. Religiosity was measured using the scale of Stephenson et al. (2008), which consisted of two dimensions. The first included beliefs about preserving bodily integrity; the second about beliefs in God. Non-religious individuals have higher registration rates (Vorstius Kruijff et al., 2018), while those who believe the body should be buried whole are less willing to register (Stephenson et al., 2008).

\section{Statistical Analysis}

The two models were compared according to: (1) how well each model fitted the data, (2) the degree of variance explained in intentions, and their capacity to predict and explain registration 
behavior (Gerend \& Shepherd, 2012). Data analysis was undertaken using Mplus version 7 (Muthén \& Muthén, 2013), using the maximum likelihood robust (MLR) estimator. Following the 2-step approach recommended by Gerbing and Anderson (1988), the unidimensionality and reliability of factors were assessed via a measurement model, and the hypothesized relationships were tested via structural equation modelling. Model fit is indicated by a non-significant chisquare $\left(\chi^{2}\right)$, a $\chi^{2}$ to degrees of freedom ratio of less than 2, a comparative fit index (CFI) greater than .90 , a root mean square error of approximation (RMSEA) less than .06, and a standardized root mean square residual (SRMR) less than .08 (Hu \& Bentler, 1999). For the confirmatory factor analysis, reliability of each factor is indicated by a composite reliability (CR) greater than .70 , and an average variance extracted (AVE) greater than .50 (Bagozzi \& Yi, 2012). Discriminant validity is indicated by the square root of each factor's AVE exceeding its correlation with other factors (Fornell \& Larcker, 1981).

Although all perception measures were gathered through a single survey, care was taken in survey design to reduce the potential for common method variance (CMV) (Podsakoff et al., 2003). Notwithstanding this preventative action, the potential influence of CMV was checked by Harman's one factor test which showed low likelihood of CMV and a more robust sensitivity test (Lindell \& Whitney, 2001) using assumed levels of CMV at $0 \%, 1 \%, 5 \%$ and $10 \%$ of the items' total variance. As reported in online supplement Table 1, all pathways remained robust with few exceptions. As these non-significant path coefficients were relatively small in the original model (for instance, the unstandardized relationship between societal inclusion and interpersonal trust was .12), an alternate possibility is that there was insufficient statistical power to detect these small effects when a high level of CMV was assumed. 


\section{Results}

\section{Descriptive Statistics and Confirmatory Factor Analysis}

Descriptive statistics are presented in the online supplement Table 2. To test the hypothesized factor structure, a confirmatory factor analysis which included all variables from the TPB and the CDB frameworks was conducted, which yielded the following fit statistics:

$\chi^{2}(\mathrm{df}=2264)=4299.019, p=.000, \chi^{2} / \mathrm{df}=1.899, \mathrm{CFI}=.926, \mathrm{RMSEA}=.042(90 \% \mathrm{CI}: .[040$, $.044])$, SRMR $=.049$. To diagnose model misspecifications, the residual correlation matrix and modification indices were inspected, which revealed a small number of non-zero residual covariances. We removed three items ("If doctors know I am an organ donor they won't try as hard to save my life" from Institutional Trust, and "Unpleasant/pleasant", "Unenjoyable/enjoyable" from Attitudes) due to cross-loadings with other items. After their removal, there appeared to be no further systematic pattern and we therefore retained the revised measurement model. The revised measurement model yielded the following fit statistics: $\chi^{2}(\mathrm{df}=2060)=3589.734, p<.001 ; \chi^{2} / \mathrm{df}=1.743, \mathrm{CFI}=.942 ; \mathrm{RMSEA}=.038(90 \%$ CI: $[.036$, $.040])$, SRMR $=.046$. In the online supplement, we present the measurement model and its standardized factor loadings, as well as an item-level correlation matrix with all indicators included.

The square root of the AVE for each factor is presented in the diagonal of the online supplement Table 2. Most factors were found to possess discriminant validity, except for Procedural and Interactional Justice. This finding suggests evaluations of procedural justice (i.e., policies, rules and regulations) are strongly entwined with interpersonal treatment received from hospital personnel. Based on a similar finding, Blader and Tyler (2003) argued that fairness 
perceptions are strongly influenced by interactions with the "authorities" responsible for communicating and implementing rules and policies. Thus, procedural justice was removed from further analyses.

\section{Comparison of theories}

The hypothesized relations as predicted by the TPB are presented in Table 1. Intention to register as an organ donor was positively and significantly related to subsequent registration behavior. In addition, both subjective norm and attitude were positively related to intention to donate. Conversely, the relationship between perceived behavioral control and intention to register was non-significant. The effects of the control variables were small, unsystematic and non-significant. Intentions explained 39\% of the variance in registration behavior at time 2 .

Insert Table 1 about here

The relationships associated with the CDB framework are presented in Table 2. Intention to register as an organ donor was positively related to registration behavior. Both distributive (H1a) and interactional (H1b) justice were positively associated with institutional trust. Social inclusion (H2) and institutional trust (H3) were positively related to trust in others. Further, institutional trust was positively associated with both normative commitment (H4a) and affective commitment (H4b). Trust in others was also positively related to normative (H5a) and affective commitment (H5b). Normative commitment was positively related to intentions to register as an organ donor (H6a), but the relationship between affective commitment and intention was nonsignificant (in contradiction of H6b). Similar to TPB, intentions explained $34 \%$ of the variance in actual registration behavior at time 2 . 
Among the control variables, religious beliefs about the body were negatively associated with both forms of commitment and intention to register. Conversely, organ donation experience was positively associated with both forms of commitment. The effects of the other controls failed to reach significance.

Insert Table 2 about here

\section{Discussion}

This study demonstrates the comparable ability of the CDB model to predict organ donation registration intentions and subsequent registration behavior relative to TPB. The CDB identifies registration intentions as a function of normative commitment to organ donation registration, stemming from trust in other society members and trust in health institutions. This is compared with the TPB where registration intentions are weakly associated with individual attitudes even though the specificity of the measured attitude matched the specificity of the behavior under consideration e.g., registration (Siegel et al., 2014). Such a result reinforces earlier findings demonstrating little value in improving favorable attitudes towards registering as an organ donor, as the association with donor registration behavior is weak at best (e.g., Morgan et al., 2008; Quick et al., 2016). Subjective norms were strongly related to registration intentions, but perceived behavioral control was not. Although past research has suggested that an individual's doubts about the ability to perform the registration act have been a barrier to registering (Vorstius Kruijff et al., 2018), the non-significant finding would suggest an increased public awareness of the ease and convenience of donor registration (Quick et al., 2016). 
The CDB model draws on theories of social exchange and collective behavior to suggest an alternative indirect set of factors (inclusion and justice perceptions) that drive donor commitment and subsequent registration behavior. The $\mathrm{CDB}$, therefore, provides additional insights into registration behavior not captured by the TPB. Although both normative and affective commitment were expected to be significantly associated with registration intentions, there are several possible explanations for the non-significance of affective commitment in the study. First, affective commitment is more likely to be a driver of ongoing prosocial behaviors, such as volunteering and blood donation, where affective commitment develops as the "cause" becomes integral to an individual's identity (Tidwell, 2005). Indeed research suggests that affective commitment is less important to an initial prosocial act, becoming salient when the behavior becomes ongoing (Callero \& Piliavin, 1983). The one-off nature of organ donor registration may therefore be less likely to foster affective commitment. Second, the high correlation between the two variables $(\mathrm{r}=0.86)$ may explain why attitudinal commitment was non-significant. Meyer and Herscovitch (2001) point to disagreement about whether the two forms of commitment are distinguishable, citing the high correlations often found between the two.

Although the efficacy of active in-person approaches to promote organ donation registration, such as training healthcare professionals in organ donation communication, has been demonstrated (Jones et al., 2017), the CDB framework suggests such focused engagement is more likely to result in favorable activation if the individual trusts health institutions. The relationship between trust and donation registration corresponds with the work of Sargeant et al. (2006) in which trust is shown to be essential to charitable donations because people cannot directly assess how well their donations are spent and so must rely on the organisation delivering 
the service. Donor registration involves an additional element of uncertainty because registration is a behavior with a long-term horizon - that is, one registers with no idea whether, when, or under what circumstances donation will actually take place. Consequently, registered donors must trust the institutions that underpin organ donation and transplant systems. Much research investigating the poor registration rates of ethnic minorities has emphasized a pervasive lack of trust in the healthcare system (Morgan et al., 2013). However, lack of trust in healthcare institutions is not simply an issue for minority populations as there are suggestions of rising consumer cynicism and scepticism towards institutions more generally (Mitchell, 2018).

The CDB model also facilitates an understanding of how to assess and ultimately promote fairness perceptions in the health institutions that individuals interact with. Justice evaluation is used as a means of gauging institutional trust, which helps people cope with the uncertainty regarding health authority actions (Colquitt et al., 2012). In this study, interactional justice contributed most to institutional trust. This may be because when people are unable to make judgments about larger institutional procedures and distributive processes, perceptions of personal interactions may serve as a proxy for overall judgments about organisations (Moorman, 1991). The significance of positive interpersonal experiences in this study is consistent with studies that find the perceived value of healthcare relates not only to instrumental outcomes but also to patient experiences within healthcare settings, such as being treated with dignity and respect in medical encounters (Mooney, 1998). Therefore, there is strong practical value in sensitizing health professionals to justice concerns to build institutional trust through improved patient interactions . 
In addition to perceptions of justice, perceptions of social inclusion help build trust in others to contribute to public goods. Grassroot engagement of individuals at the local level through community events have been shown to be an effective means to improve social inclusion perceptions (i.e., Polonsky \& Arambewela, 2015). Indeed, cultural festivals are commonly subsidized through a 'social equity' argument, where outcomes of inclusion are advocated (see Getz, 2009).

Notwithstanding the alternative pathways to donor registration behavior, both the TPB and CDB models have a strong normative basis. This suggests that norm-based messages promoting organ donation registration are useful. Marketing communications underpinned by TPB would stress the pressure for registration by family and friends (subjective norms). In contrast, marketing communications underpinned by the CDB model would focus on the moral obligation to others (normative commitment). Importantly focusing on a collective responsibility to register and a shared fate around the issue of organ donation and transplantation may be a way to motivate those whose failure to register is founded on inertia rather than negative perceptions of deceased donation and transplantation.

\section{Limitations and Future Research}

While the online panel used in the study was reflective of the Australian population, it is inevitably biased towards people who are motivated to join panels. Consequently, some of the country's more vulnerable populations were likely to be excluded from the sample. Given that minority groups, such as migrants and other ethnic minority populations, are less likely to register as donors, the potential omission of such groups has probably reduced the variance in responses. This suggests that the results may well underestimate the influence of social inclusion, 
justice, and trust on donor registration. Despite the relatively high mean scores for these constructs, the CDB pathways were nonetheless significant. Future research may focus on assessing the strength of the $\mathrm{CDB}$ model with marginalized populations in comparison with the general population.

Second, although social exchange theory underpins the CDB model where trust is the key mediator, an alternative mediating pathway could be social identity. This is because the development and maintenance of a favorable identity stemming from interactional justice perceptions strongly influences cooperation that is discretionary in nature (Blader \& Tyler, 2003). Indeed, consumers who strongly identify with a cause or organization are motivated to engage in acts that help the firm to achieve its goals (Bhattacharya \& Sen, 2003). Thus future research could test this alternative mediating variable.

\section{Conclusion}

The aim of this paper was to test an alternative framing to organ registration that draws attention away from the individual's attitude towards organ donation, to refocus on the individual's interactions within his/her community and institutions. The CDB model is useful in predicting organ registration intentions and behavior and is of comparable performance to the TPB. Further, it also provides a level of specificity about drivers of donor registration behavior not found in the TPB. For example, a central criticism of the TPB is that it provides little insight to guide the design of interventions to effect behavioral change (Sniehotta et al., 2014). In contrast, the CDB suggests a number of focus areas for policymakers and public service announcements. These include building community inclusiveness and trust in health institutions so that a shared fate in relation to donation and transplantation is fostered. In summary, the TPB and the CDB come 
with their own inherent strengths and limitations but as illustrated here, their differential contribution to understanding the donor registration act is promising. 


\section{References}

Allen, N. J., \& Meyer, J. P. (1990). The measurement and antecedents of affective, continuance and normative commitment to the organization. Journal of Occupational Psychology, $63(1), 1-18$.

Almassi, B. (2014). Trust and the duty of organ donation. Bioethics, 28(6), 275-283.

Armitage, C. J., \& Conner, M. (2001). Efficacy of the theory of planned behaviour: A metaanalytic review. British Journal of Social Psychology, 40(4), 471-499.

Bagozzi, R. P., \& Yi, Y. (2012). Specification, evaluation, and interpretation of structural equation models. Journal of the Academy of Marketing Science, 40(1), 8-34.

Bednall, T. C., Bove, L. L., Cheetham, A., \& Murray, A. L. (2013). A systematic review and meta-analysis of antecedents of blood donation behavior and intentions. Social Science and Medicine, 96, 86-94.

Bhattacharya, C. B., \& Sen, S. (2003). Consumer-company identification: A framework for understanding consumers' relationships with companies. Journal of Marketing, 67(2), 7688.

Blader, S. L., \& Tyler, T. R. (2003). A four-component model of procedural justice: Defining the meaning of a "fair" process. Personality and Social Psychology Bulletin, 29, 747-758.

Blau, P. M. (1964). Exchange and power in social Life. New York: Wiley.

Bosancianu, C. M., Powell, S. \& Bratović, E. (2013). Social capital and pro-social behavior online and offline. International Journal of Internet Science 8(1), 49-68. 
Boulware, L. E., Ratner, L. E., Cooper, L. A., Sosa, J. A., LaVeist, T. A., \& Powe, N. R. (2002). Understanding disparities in donor behavior: Race and gender differences in willingness to donate blood and cadaveric organs. Medical Care, 40(2), 85-95.

Boulware, L. E., Troll, M. U., Wang, N. Y. \& Powe, N. R. (2006). Public attitudes toward incentives for organ donation: A national study of different racial/ethnic and income groups. American Journal of Transplantation, 6(11), 2774-2785.

Bradford, B. (2014). Policing and social identity: Procedural justice, inclusion and cooperation between police and public. An International Journal of Research and Policy, 24(1), $22-43$.

Bresnahan, M., Lee, S. Y., Smith, S. W., Shearman, S., Nebashi, R., Park, C. Y., \& Yoo, J. (2007). A theory of planned behavior study of college students' intention to register as organ donors in Japan, Korea, and the United States. Health Communication, 21(3), 201-211.

Brewer, M. B. (2008). Depersonalized trust and in group cooperation. In J Krueger \& Joachim I. (Ed). Rationality and social responsibility: Essays in honor of Robyn Mason Dawes. Modern pioneers in psychological science: An APS-psychology press series (pp. 215-232). New York, NY: Psychology Press.

Brown, S. J. (2018). Autonomy, trust and ante-mortem interventions to facilitate organ donation. Clinical Ethics, 13(3), 143-150.

Burkell, J. A., Chandler, J. A., \& Shemie, S. D. (2013). Attitudes toward reciprocity systems for organ donation and allocation for transplantation. Journal of Health Politics, Policy and Law, 38(5), 957-986.

Callero, P. L., \& Piliavin, J. A. (1983). Developing a commitment to blood donation: The impact 
of one's first experience. Journal of Applied Social Psychology, 13(1), 1-16.

Colquitt, J. A. (2001). On the dimensionality of organizational justice: A construct validation of a measure. Journal of Applied Psychology, 86(3), 386-400.

Colquitt, J. A., LePine, J. A., Piccolo, R. F., Zapata, C. P, \& Rich, B. L. (2012). Explaining the justic-performance relationship: Trust as exchange deepener or trust as uncertainty reducer? Journal of Applied Psychology, 97(1), 1-15.

Donate Life America. (2019). How you can help educate others about organ, eye and tissue donation. https://www.donatelife.net/things-you-can-do/educate-others/, accessed May 28, 2019.

Etzioni, A. (2003). Organ donation: A communitarian approach. Kennedy Institute of Ethics Journal, 13(1), 1-18.

Falomir-Pichastor, J. M., Berent, J. A., \& Pereira, A. (2013). Social psychological factors of post-mortem organ donation: A theoretical review of determinants and promotion strategies. Health Psychology Review, 7(2), 202-247.

Farsides, T. (2010). Perceived responsibility to act: An investigation with respect to registering willingness to become a postjumous organ donor. British Journal of Psychology, 101(3), $503-517$.

Fishbein, M., \& Ajzen, I. (2010). Predicting and Changing Behavior: The Reasoned Action Approach. New York, NY: Psychology Press. 
Foddy, M., \& Dawes, R. M. (2008). Group-based trust in social dilemmas. In A. Biel, D. Eek, T. Gärling, \& M. Gustafsson (Eds.). New Issues and Paradigms in Research on Social Dilemmas, 57-71.

Fornell, C. and Larcker, D. F. (1981). Evaluating structural equation models with unobservable variables and measurement error. Journal of Marketing Research, 18(1), 39-50.

Giesler, M. (2006). Consumer gift systems. Journal of Consumer Research, 33(2), 283-290.

Gerbing, D. W., \& Anderson, J. C. (1988). An updated paradigm for scale development incorporating unidimensionality and its assessment. Journal of Marketing Research, 25(2), $186-192$.

Gerend, M. A., \& Shepherd, J. E. (2012). Predicting human papillomavirus vaccine uptake in young adult women: Comparing the health belief model and theory of planned behavior. Annals of Behavioral Medicine, 44(2), 171-180.

Getz, D. (2009). The nature and scope of festival studies. International Journal of Event Management Research. 5(1), 61-78.

Godin, G., Bélanger-Gravel, A., Gagné, C., \& Blondeau, D. (2008). Factors predictive of signed consent for posthumous organ donation. Progress in Transplantation, 18(2), 109-117.

Goldberg, D. S., Halpern, S. D., \& Reese, P. P. (2013). Deceased organ donation consent rates among racial and ethnic minorities and older potential donors. Critical Care Medicine, 41(2), 496-505.

Gouldner, A. W. (1960). The norm of reciprocity: A preliminary statement. American 
Sociological Review, 25(2), 161-178.

Granovetter, M. (1985). Economic action and social structure: The problem of embeddedness. American Journal of Sociology, 91(3) 481-510.

Healy, K. (2004). Altruism as an organisational problem: The case of organ procurement. American Sociological Review, 69(3), 387-404.

Hyde, M. K., Knowles, S. R., \& White, K. M. (2013). Donating blood and organs: Using an extended theory of planned behavior perspective to identify similarities and differences in individual motivations to donate. Health Education Research, 28, 1092-1104.

HRSA-Health Resources \& Service Administration (2019). U.S. Government information on organ donation and transplantation. https://www.organdonor.gov/, accessed May 28, 2019.

Hillebrandt, H., Sebastian, C., \& Blakemore, S. J. (2011). Experimentally induced social inclusion influences behavior on trust games. Cognitive Neuroscience, 2(1), 27-33.

Horton, R. L., \& Horton, P. J. (1991). A model of willingness to become a potential organ donor. Social Science \& Medicine, 33(9), 1037-1051.

Hu, L., \& Bentler, P. M. (1999). Cutoff criteria for fit indexes in covariance structure analysis: Conventional criteria versus new alternatives. Structural Equation Modeling, 6(1), 1-55.

Hyde, M. K., Knowles, S. R., \& White, K. M. (2013). Donating blood and organs: using an extended theory of planned behavior perspective to identify similarities and differences in individual motivations to donate. Health Education Research, 28(6), 1092-1104. 
Irving, M. J., Tong, A., Jan, S., Cass, S., Rose, J., Chadban, S., Allen, R. D., Craig, J. C., Wong, G., \& Howard, K. (2012). Factors that influence the decision to be an organ donor: a systematic review of the qualitative literature. Nephrol Dial Transplant, 27(6), 2526-2533.

Israni, A. K., Zaun, D., Rosendale, J.D, Schaffhausen, C., Snyder, J. J., \& Kasiske, B. L. (2019). OPTN/SRTR 2017 Annual data report: Deceased organ donation. American Society of Transplant Surgeons, 19 (S2),1-23.

Jones, C. P, Papadopoulos, C., \& Randhawa, G. (2017). Primary care interventions to encourage organ donation registration: A systematic review. Transplantation Reviews, 31(4), 268275.

Katz, H., Blekher, M., \& Bosch, D. A. (2019). It is all about control: Understanding reluctance to register for organ donation. Nonprofit and Voluntary Sector Quarterly, 48(3), 665-680.

Kline, R. B. (2011). Principles and Practice of Structural Equation Modeling (3rd ed.). New York: The Guildford Press.

Kocher, Martin G., Martinsson, P., Matzat, D., \& Wollbrant, C. (2015). The role of beliefs, trust, and risk in contributions to a public good. Journal of Economic Psychology, 51(12), 236244.

Konovsky, M. A., \& Pugh, S. D. (1994). Citizenship behavior and social exchange. Academy of Management Journal, 37(3), 656-669.

Kopfman, J. E., \& Smith, S. W. (1996). Understanding the audiences of a health communication campaign: A discriminant analysis of potential organ donors based on intent to donate. Journal of Applied Communication Research, 24(1), 33-49. 
Kopfman, J. E., Smith, S. W., Ah Yun, J. K., \& Hodges, A. (2009). Affective and cognitive reactions to narrative versus statistical evidence organ donation messages. Journal of Applied Communication Research, 26(3), 279-300.

Lawler, E. J., Thye, S. R., \& Yoon, J. (2001). Emotion and group cohesion in productive exchange. American Journal of Sociology, 106(3), 616-657.

Le, H., Polonsky, M. \& Arambewela, R. (2015). Social inclusion through cultural engagement among ethnic communities, Journal of Hospitality Marketing \& Management, 24(4), 375400.

Levi, M. (1991). Are there limits to rationality? European Journal of Sociology, 32(1), 130-141.

Levi, M. (1998). A state of trust. In A. Braithwaite \& M. Levi (Eds.), Trust and governance (pp. 1-18). New York, NY: Russell Sage Foundation.

Lindell, M. K., \& Whitney, D. J. (2001). Accounting for common method variance in crosssectional research designs. Journal of Applied Psychology, 86(1), 114-121.

Liou, K. T., \& Nyhan, R. C. (1994). Dimensions of organisational commitment in the public sector: An empirical assessment. Public Administration Quarterly, 18(1), 99-118.

Malone, G. P., Pillow, D. R., \& Osman, A. (2012). The general belongingness scale (GBS): Assessing achieved belongingness. Personality and Individual Differences, 52(3), $311-$ 316.

Mau, S. (2004). Welfare regimes and the norms of social exchange. Current Sociology, 52(1), 53-74. 
McComas, K., Tuite, L. S., Waks, L., \& Sherman, L. A. (2007). Predicting satisfaction and outcome acceptance with advisory committee meetings: The role of procedural justice. Journal of Applied Social Psychology, 37(5), 905-927.

Meyer, J. P., \& Allen, N. J. (1991). A three-component conceptualisation of organisational commitment. Human Resource Management Review, 1(1), 61-89.

Meyer, J. P., \& Herscovitch, L. (2001). Commitment in the workplace toward a general model. Human Resource Management Review, 11, 299-326.

Meyer, J. P., Stanley, D. J., Herscovitch, L., \& Topolnytsky, L. (2002). Affective, continuance, and normative commitment to the organisation: A meta-analysis of antecedents, correlates, and consequences. Journal of Vocational Behavior, 61(1), 20-52.

Mitchell, V. (2018). Why customer trust is more vital to brand survival than it's ever been. https://www.cmo.com.au/article/642102/why-customer-trust-more-vital-brand-survivalthan-it-ever-been/ Accessed 19/06/2019

Molm, L. D. (2010). The structure of reciprocity. Social Psychology Quarterly, 73(2), 119-131.

Molm, L. D., Collett, J. L., \& Schaefer, D. R. (2007). Building solidarity through exchange: A theory of reciprocity. American Journal of Sociology, 113(1), 205-242.

Molm, L. D., Takahashi, N., \& Peterson, G. (2000). Risk and trust in social exchange: An experimental test of a classical proposition. American Journal of Sociology, 105(5), 13961427.

Mooney, G. (1998). Beyond health outcomes: The benefits of health care. Health Care Analysis, 
6(2), 99-105.

Moorman, R. H. (1991). Relationship between organisational justice and organisational citizenship behaviors: Do fairness perceptions influence employee citizenship? Journal of Applied Psychology, 76, 845-855

Morgan, M., Kenten, C., \& Deedat, S. (2013). Attitudes to deceased organ donation and registration as a donor among minority ethnic groups in North America and the UK: A systhesis of quantitative and qualitative research. Ethnicity \& Health, 18(4), 367-390.

Morgan, M., Mayblin, M., \& Jones, R. (2008). Ethnicity and registration as a kidney donor: The significance of identity and belonging. Social Science \& Medicine, 66(1), 147-158.

Morgan, S. \& Miller, J. (2002). Communicating about gifts of life: the effect of knowledge, attitudes, and altruism on behavior and behavioral intentions regarding organ donation. Journal of Applied Communication Research, 30(2), 163-178.

Muthén, K. L., \& Muthén, B. (2019). Mplus. Statmodel.com

Newton, J. D., Newton, F. J., Ewing, M. T., \& Burney, S. (2013). Conceptual overlap between moral norms and anticipated regret in the prediction of intention: Implications for theory of planned behaviour research. Psychology \& Health, 28(5), 495-513.

Nijkamp, M. D., Hollestelle, M. L., Zeegers, M. P., van den Borne, B., \& Reubsaet, A. (2008). To be(come) or not to be(come) an organ donor, that's the question: a meta-analysis of determinant and intervention studies. Health Psychology Review, 2(1), 20-40. 
O’Carroll, R. E., Shepherd, L., Hayes, P. C. \& Feruson, E. (2016). Anticipated regret and organ donor registration: A randomized controlled trial. Health Psychology, 35(11), 1169-1177.

Park, H. S., \& Smith, S. W. (2007). Distinctiveness and influence of subjective norms, personal descriptive and injunctive norms, and societal descriptive and injunctive norms on behavioral intent: A case of two behaviors critical to organ donation. Human Communication Research, 33(2), 194-218.

Podsakoff, P. M., MacKenzie, S. B., Jeong-Yeon, L. \& Podsakoff, N. P. (2003). Common method biases in behavioral research: a critical review of the literature and recommended remedies. The Journal of Applied Psychology, 88(5), 879-903.

Quick, B. L., Anker, A. E., Feeley, T. H., \& Morgan, S. E. (2016). An examination of three theoretical models to explain the organ donation attitude-registration discrepancy among mature adults. Health Communication, 31(3), 265-274.

Robinson, D. H., Perryman, J. P., Thompson, N. J., Amaral, S., \& Arriola, K. R. J. (2012). Testing the utility of a modified organ donation model among African American adults. Journal of Behavioral Medicine, 35(3), 364-374.

Rocheleau, C. A. (2013). Organ donation intentions and behaviors: Application and extension of the theory of planned behavior. Journal of Applied Social Psychology, 43(1), 201-213.

Rothstein, B. (2000). Trust, social dilemmas and collective memories. Journal of Theoretical Politics, 12(4), 477-501.

Rothstein, B. (2001). The universal welfare state as a social dilemma. Rationality and Society, 13(2), 213-233. 
Rumsey, S., Hurford, D. P., \& Cole, A. K. (2003). Influence of knowledge and religiousness on attitudes toward organ donation. Transplantation Proceedings, 35(8), 2845-2850.

Sander, S. L., \& Miller, B. K. (2005). Public knowledge and attitudes regarding organ and tissue donation: An analysis of the northwest Ohio community. Patient Education and Counseling, 58(2), 154-163.

Sargeant, A., \& Lee, S. (2004). Trust and relationship commitment in the United Kingdom voluntary sector: Determinants of donor behavior. Psychology \& Marketing, 21(8), 613635.

Sargeant, A. Ford, J. B., \& West, D. C. (2006). Perceptual determinants of nonprofit giving behavior. Journal of Business Research, 59(2), 155-165.

Savulescu, J. (2003). Death, us and our bodies: Personal reflections. Journal of Medical Ethics, 29(3), 127-130.

Schweda, M., \& Schicktanz, S. (2009). Public ideas and values concerning the commercialization of organ donation in four European countries. Social Science \& Medicine, 68(6), 1129-1136.

Shacham E, Loux T, Barnidge EK, Lew D, Pappaterra L. (2018). Determinants of organ donation registration. American Journal of Transplantation, 18(11), 2798-2803.

Shaw, R., Bell, L., \& Webb, R. (2012). New Zealanders' perceptions of gift and giving back as participants of organ transfer procedures. Kotuitui: New Zealand Journal of Social Sciences Online, 7(1), 26-36. 
Sheldon, K. M., \& Gunz, A. (2009). Psychological needs as basic motives, not just experiential requirements. Journal of Personality, 77(5), 1467-1492.

Siegal, G., \& Bonnie, R. J. (2006). Closing the organ gap: A reciprocity-based social contract approach. The Journal of Law, Medicine \& Ethics, 34(2), 415-423.

Siegel, J. T., Alvaro, E. M., Crano, W. D., Lac, A., Ting, S., \& Jones, S. P. (2008). A quasiexperimental investigation of message appeal variations on organ donor registration rates. Health Psychology, 27(2), 170-178.

Siegel, J. T., Navarro, M. A., Tan, C. N., \& Hyde, M. K. (2014). Attitude-behavior consistency, the principle of compatibility, and organ donation: A classic innovation. Health Psychology, 33(9), 1084-1091.

Siminoff, L. A., \& Arnold, R. (1999). Increasing organ donation in the African-American community: Altruism in the face of an untrustworthy system. Annals of Internal Medicine, 130(7), 607-609.

Siminoff, L. A., Burant, C. J., \& Ibrahim, S. A. (2006). Racial disparities in preferences and perceptions regarding organ donation. Journal of General Internal Medicine, 21(9), 9951000.

Sniehotta, F. F., Presseau, J., \& Araújo-Soares, V. (2014). Time to retire the theory of planned behaviour. Health Psychology Review, 8(1), 1-7.

Stephenson, M. T., Morgan, S. E., Roberts-Perez, S. D., Harrison, T., Afifi, W., \& Long, S. D. (2008). The role of religiosity, religious norms, subjective norms, and bodily integrity in signing an organ donor card. Health Communication, 23(5), 436-47. 
Tabachnick, B. G., \& Fidell, L. S. (2001). Using Multivariate Statistics (5th ed.). Pearson.

Terry, D. J., Hogg, M. A., \& White, K. M. (1999). The theory of planned behaviour: selfidentity, social identity and group norms. British Journal of Social Psychology, 38(3), 225244.

Tidwell, M. V. (2005). A social identity model of prosocial behaviors within nonprofit organisations. Nonprofit Management \& Leadership, 15(4), 449-467.

Twenge, J. M., DeWall, C. N., Bartels, J. M., Ciarocco, N., \& Baumeister, R. F. (2007). Social exclusion decreases prosocial behavior. Journal of Personality and Social Psychology, 92(1), 56-66.

Tyler, T., Degoey, P., \& Smith, H. (1996). Understanding why the justice of group procedures matters: A test of the psychological dynamics of the group-value model. Journal of Personality and Social Psychology, 70(5), 913-930.

Vorstius Kruijff, P. E., Witjes, M., Jansen, N. E., \& Slappendel, R. (2018). Barriers to registration in the national donor registry in nations using the opt-in system: A review of the literature. Transplantation Proceedings, 50(10), 2997-3009.

Yamagishi, T., \& Cook, K. S. (1993). Generalized exchange and social dilemmas. Social Psychology Quarterly, 56(4), 235-248.

Yamagishi, T., \& Kiyonari, T. (2000). The group as the container of generalized reciprocity. Social Psychology Quarterly, 63(2), 116-132. 


\section{Biographies}

Emma Tinning is health researcher specializing in policy development in the not for profit and government sectors. She is currently working with the Royal Commission into Victoria's Mental Health System. In 2019 she developed Australia's first National Strategic Action Plan for Kidney Disease.

Tim Bednall is a Senior Lecturer in Management at Swinburne Business School in the Department of Management and Marketing. He is a registered psychologist who specializes in employee learning, expertise and innovation. He also has a strong interest in business education of advanced research methods.

Liliana Bove is a Professor in Marketing at the University of Melbourne, Department of Management and Marketing. She investigates prosocial behavior by customers and has extended this interest to the context of blood and organ donors.

Helen Jordan is an Associate Professor in Public Health at the University of Melbourne. She specializes in public health planning, program evaluation and health policy where she applies systems thinking. 


\section{Tables}

Table 1. Theory of Planned Behavior: Standardized Path Coeffcients for Structural Model

\begin{tabular}{lcc}
\hline & $\begin{array}{c}\text { Intention to } \\
\text { Register }\end{array}$ & $\begin{array}{c}\text { Registration as a } \\
\text { Donor }\end{array}$ \\
\hline Attitude & $.11^{*}$ & $.57 * * *$ \\
Subjective Norm & .07 & -.21 \\
Perceived Behavioural Control & & $.63 * * *$ \\
Intention to Register & -.07 & \\
Religiosity (Beliefs about Body) & -.01 & \\
Religiosity (Beliefs about God) & .00 & .39 \\
Knowledge of Organ Donation & .02 & \\
Organ Donation Experience & & .45 \\
& & \\
& & \\
& & \\
\hline Note. $* p<.05, * * p<.01, * * * p<.001$. Model fit: $\chi^{2}(\mathrm{df}=154)=473.665, p<.001$, \\
$\chi^{2} / \mathrm{df}=1.899$, CFI $=.941$, RMSEA $=.064(90 \% \mathrm{CI}:[.057, .070]), \mathrm{SRMR}=.074$.
\end{tabular}


Table 2. Collective Donor Behavior Framework: Standardized Path Coeffcients for the Structural Model

\begin{tabular}{|c|c|c|c|c|c|c|}
\hline & $\begin{array}{c}\text { Institutional } \\
\text { Trust }\end{array}$ & $\begin{array}{l}\text { Trust in } \\
\text { Others }\end{array}$ & $\begin{array}{c}\text { Normative } \\
\text { Commitment }\end{array}$ & $\begin{array}{c}\text { Affective } \\
\text { Commitment }\end{array}$ & $\begin{array}{l}\text { Intention to } \\
\text { Register }\end{array}$ & $\begin{array}{c}\text { Registration } \\
\text { as a Donor }\end{array}$ \\
\hline Distributive Justice & $.17 * *$ & & & & & \\
\hline Interactional Justice & $.39 * * *$ & & & & & \\
\hline Social Inclusion & & $.14^{*}$ & & & & \\
\hline Institutional Trust & & $.23 * * *$ & $.27 * * *$ & $.24 * * *$ & & \\
\hline Trust in Others & & & $.16^{* *}$ & $.20 * * *$ & & \\
\hline Normative Commitment & & & & & $.65 * * *$ & \\
\hline Affective Commitment & & & & & -.03 & \\
\hline Intention to Register & & & & & & $.59 * * *$ \\
\hline Religiosity (Beliefs about & & & & & & \\
\hline Body) & & & $-.15 *$ & $-.17 * *$ & $-.09 *$ & \\
\hline Religiosity (Beliefs about God) & & & .01 & .10 & -.02 & \\
\hline Knowledge of Organ Donation & & & -.04 & -.06 & .03 & \\
\hline Organ Donation Experience & & & $.18 * * *$ & $.22 * * *$ & .03 & \\
\hline $\mathrm{R}^{2}$ & .27 & .09 & .19 & .21 & .45 & .34 \\
\hline
\end{tabular}




\section{Figures}

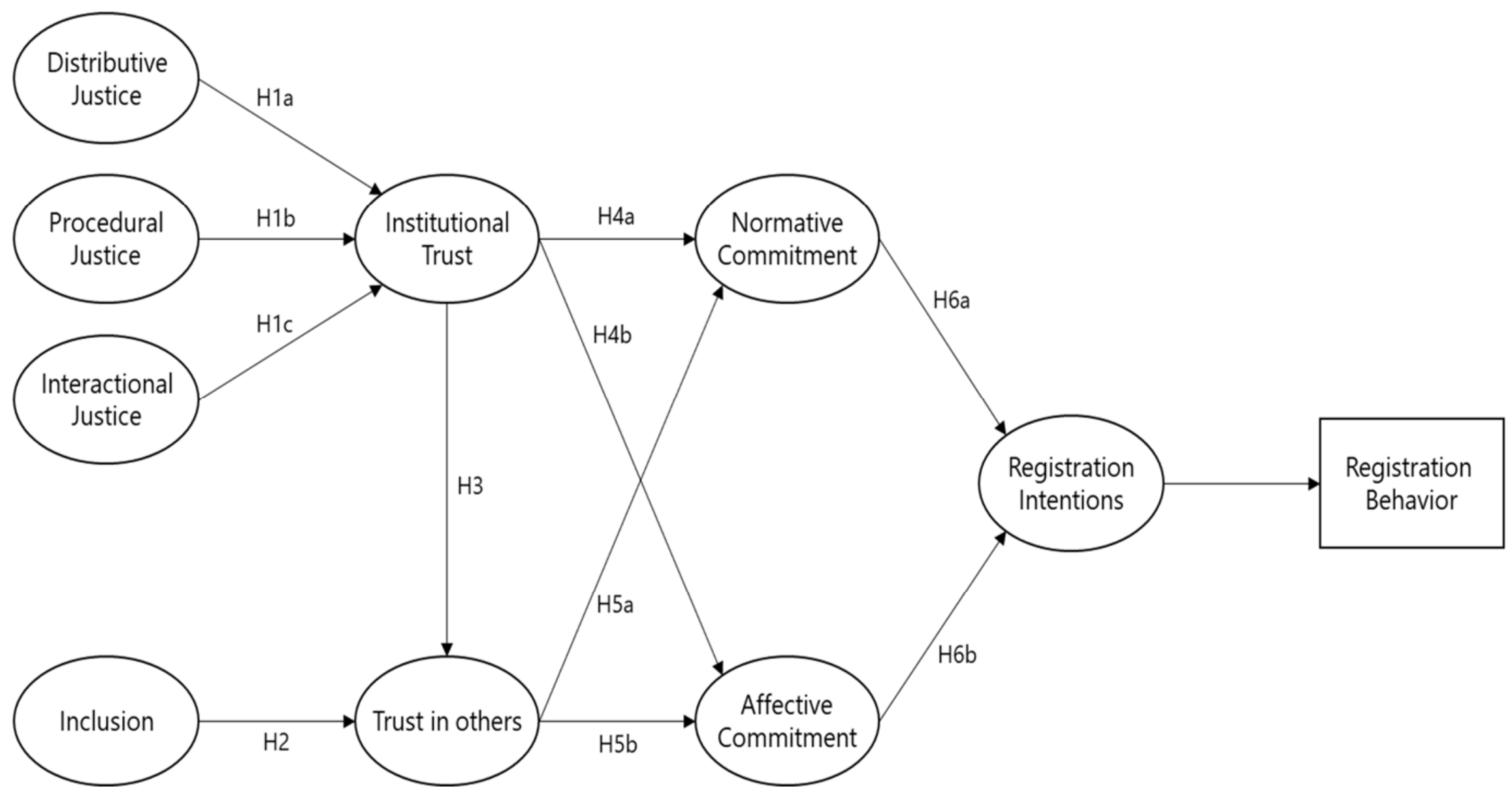

Figure 1. The Collective Donor Behavior Model 


\section{Online Supplement}

Table 1. Common Method Variance (CMV) Sensitivity Test

\begin{tabular}{|c|c|c|c|c|}
\hline \multirow[b]{2}{*}{ Structural Paths } & \multicolumn{4}{|c|}{$\begin{array}{l}\text { CMV Assumed \% of Total } \\
\text { Variance Among Indicators }\end{array}$} \\
\hline & $0 \%$ & $1 \%$ & $5 \%$ & $10 \%$ \\
\hline \multicolumn{5}{|l|}{ Theory of Planned Behavior } \\
\hline Attitude -> Intentions & $.14^{*}$ & $.14 *$ & $.14^{*}$ & $.14^{*}$ \\
\hline Subjective Norm -> Intentions & $.84 * * *$ & $.85 * * *$ & $.85 * * *$ & $.85 * * *$ \\
\hline Perceived Behavioural Control -> Intentions & .11 & .11 & $.11 *$ & $.11 *$ \\
\hline Religiosity (Beliefs about Body) -> Intentions & -.09 & -.09 & -.10 & -.10 \\
\hline Religiosity (Beliefs in God) -> Intentions & -.01 & -.01 & -.01 & -.01 \\
\hline \multicolumn{5}{|l|}{ Donor Behavior Model } \\
\hline Interactional Justice- $>$ Institutional Trust & $.14 * *$ & $.14 * *$ & $.12 *$ & $.11^{*}$ \\
\hline Distributive Justice -> Institutional Trust & $.32 * * *$ & $.32 * * *$ & $.30 * * *$ & $.28 * * *$ \\
\hline Institutional Trust -> Interpersonal Trust & $.23 * * *$ & $.23 * *$ & $.20 * *$ & $.17 *$ \\
\hline Societal Inclusion -> Interpersonal Trust & $.12 *$ & $.12 *$ & $.10 *$ & .07 \\
\hline Institutional Trust $->$ Normative Commitment & $.41 * * *$ & $.41 * * *$ & $.39 * * *$ & $.37 * * *$ \\
\hline Interpersonal Trust $->$ Normative Commitment & $.25 * *$ & $.24 * *$ & $.22 *$ & .18 \\
\hline Religiosity (Body) -> Normative Commitment & $-.18 *$ & $-.18 *$ & $-.17 *$ & -.15 \\
\hline $\begin{array}{l}\text { Religiosity (Belief in God) -> Normative } \\
\text { Commitment }\end{array}$ & .00 & .01 & 0.01 & .02 \\
\hline Institutional Trust $->$ Affective Commitment & $.31 * * *$ & $.31 * * *$ & $.29 * * *$ & $.27 * *$ \\
\hline Interpersonal Trust $->$ Affective Commitment & $.26 * * *$ & $.26 * * *$ & $.24 * *$ & $.21 *$ \\
\hline Religiosity (Body) -> Affective Commitment & $-.19 * *$ & $-.18 * *$ & $-.18 *$ & $-.16^{*}$ \\
\hline $\begin{array}{l}\text { Religiosity (Belief in God) -> Affective } \\
\text { Commitment }\end{array}$ & .07 & .07 & .07 & $.08^{*}$ \\
\hline Normative Commitment $->$ Intentions & $.75 * * *$ & $.74 * * *$ & $.74 * * *$ & $.74 * * *$ \\
\hline Affective Commitment -> Intentions & -0.04 & -0.04 & -0.05 & -0.05 \\
\hline Religiosity (Beliefs about Body) -> Intentions & $-.13 *$ & $-.13 *$ & $-.12 *$ & $-.12 *$ \\
\hline Religiosity (Beliefs in God) -> Intentions & -.02 & -.02 & -.02 & -.02 \\
\hline
\end{tabular}

Note: $* p<.05, * * p<.01, * * * p<.001$. All path coefficients are unstandardized. 
Table 2. Means, Standard Deviations and Correlations Among Variables

\begin{tabular}{|c|c|c|c|c|c|c|c|c|c|c|c|c|c|c|c|c|c|}
\hline & 1 & 2 & 3 & 4 & 5 & 6 & 7 & 8 & 9 & 10 & 11 & 12 & 13 & 14 & 15 & 16 & 17 \\
\hline 1. Registered as a Donor $(0=$ No, $1=$ Yes $)$ & -- & -.01 & -.01 & .11 & $.19 * *$ & -.02 & $.25 * * *$ & .01 & .11 & .03 & .05 & .04 & .05 & $.20 * * *$ & $.15^{*}$ & -.10 & .02 \\
\hline 2. Knowledge of Organ Donation & -.07 & -- & $-.14 * *$ & $.13^{* *}$ & .08 & $.21 * * *$ & $.09 *$ & $.25 * * *$ & -.07 & $.17 * * *$ & .05 & .09 & .05 & .00 & .04 & $-.35^{* * *}$ & $-.13 * *$ \\
\hline 3. Organ Donation Experience & .01 & -.07 & -- & $.15 * * *$ & $.23 * * *$ & -.01 & $.16^{* * *}$ & .05 & .07 & .05 & -.05 & -.04 & -.04 & $.25 * * *$ & $.19 * * *$ & .01 & $.11^{*}$ \\
\hline 4. Attitude & .11 & $.14^{* *}$ & $.15^{* *}$ & $(.85)$ & $.47 * * *$ & $.15^{* * *}$ & $.44 * * *$ & $.42 * * *$ & $.30 * * *$ & $.23 * * *$ & $.19 * * *$ & $.25 * * *$ & $.23 * * *$ & $.44 * * *$ & $.51 * * *$ & $-.40^{* * *}$ & $-.10^{*}$ \\
\hline 5. Subjective Norm & $.22 * * *$ & .06 & $.27 * * *$ & $.51 * * *$ & $(.76)$ & $.14 * *$ & $.58 * * *$ & $.27 * * *$ & $.22 * * *$ & $.22 * * *$ & $.14^{* *}$ & $.13^{* *}$ & $.15^{* * *}$ & $.59 * * *$ & $.69 * * *$ & $-.16^{* * *}$ & -.03 \\
\hline 6. Perceived Behavioral Control & -.03 & $.21 * * *$ & -.01 & $.17^{* *}$ & $.15^{*}$ & $(.90)$ & $.18 * * *$ & $.27 * * *$ & .05 & $.30 * * *$ & $.27 * * *$ & $.23 * * *$ & $.23 * * *$ & .04 & $.10^{*}$ & $-.19^{* * *}$ & -.01 \\
\hline 7. Intention to Register & $.25 * * *$ & $.09 *$ & $.16^{* *}$ & $.45 * * *$ & $.66 * * *$ & $.19 * * *$ & $(.96)$ & $.26 * * *$ & $.13^{* *}$ & $.17 * * *$ & .04 & $.09^{*}$ & $.11^{*}$ & $.51 * * *$ & $.63 * * *$ & $-.22 * * *$ & -.06 \\
\hline 8. Institutional Trust & .02 & $.23 * * *$ & .06 & $.44 * * *$ & $.27 * * *$ & $.26 * * *$ & $.26 * * *$ & $(.86)$ & $.29 * * *$ & $.31 * * *$ & $.45 * * *$ & $.49 * * *$ & $.48 * * *$ & $.29 * * *$ & $.34 * * *$ & $-.32^{* * *}$ & -.08 \\
\hline 9. Trust in Others & .07 & $-.10^{*}$ & .07 & $.31 * * *$ & $.23 * *$ & .03 & $.12 *$ & $.27 * * *$ & $(.89)$ & $.21^{* * *}$ & $.33 * * *$ & $.40^{* * *}$ & $.39 * * *$ & $.28 * * *$ & $.25 * * *$ & -.04 & $.10^{*}$ \\
\hline 10. Social Inclusion & .04 & $.18 * * *$ & .04 & $.25 * * *$ & $.22 * * *$ & $.32 * * *$ & $.17 * *$ & $.31 * * *$ & $.20 * * *$ & $(.88)$ & $.39 * * *$ & $.38 * * *$ & $.41 * * *$ & $.17 * * *$ & $.23 * * *$ & $-.17 * * *$ & $.12 * *$ \\
\hline 11. Distributive Justice & .00 & .07 & -.06 & $.19 * * *$ & $.12 *$ & $.30 * * *$ & .03 & $.45 * * *$ & $.30 * * *$ & $.40 * * *$ & $(.81)$ & $.70^{* * *}$ & $.78 * * *$ & $.13^{* *}$ & $.16 * * *$ & -.04 & .03 \\
\hline 12. Interactional Justice & .00 & $.09^{*}$ & -.04 & $.27 * * *$ & .11 & $.25 * * *$ & .09 & $.50 * * *$ & $.40 * * *$ & $.40 * * *$ & $.70 * * *$ & $(.91)$ & $.86 * * *$ & $.19 * * *$ & $.19 * * *$ & $-.14 * *$ & .02 \\
\hline 13. Procedural Justice & .00 & .07 & -.05 & $.27 * * *$ & $.14^{*}$ & $.26 * * *$ & $.12 *$ & $.52 * * *$ & $.40 * * *$ & $.43 * * *$ & $.79 * * *$ & $.92 * * *$ & $(.80)$ & $.19 * * *$ & $.21 * * *$ & $-.14 * *$ & .02 \\
\hline 14. Affective Commitment & $.19 * * *$ & .01 & $.25 * * *$ & $.46^{* * *}$ & $.69 * * *$ & .05 & $.53 * * *$ & $.32 * * *$ & $.29 * * *$ & $.17^{* *}$ & $.12 *$ & $.20 * * *$ & $.20 * * *$ & $(.91)$ & $.79 * * *$ & $-.14 * *$ & .08 \\
\hline 15. Normative Commitment & $.15^{* *}$ & .04 & $.21 * * *$ & $.55 * * *$ & $.81 * * *$ & $.11^{*}$ & $.66^{* * *}$ & $.36 * * *$ & $.25^{* * *}$ & $.22 * * *$ & $.15^{* *}$ & $.20 * * *$ & $.23 * * *$ & $.86^{* * *}$ & $(.85)$ & $-.16^{* * *}$ & -.01 \\
\hline 16. Religiosity (Beliefs about Body) & -.04 & $-.36 * * *$ & -.01 & $-.46 * * *$ & $-.18^{* *}$ & $-.19 * * *$ & $-.24 * * *$ & $-.33 * * *$ & -.03 & $-.19 * * *$ & -.06 & $-.15^{* *}$ & $-.16^{* *}$ & $-.19 * * *$ & $-.21 * * *$ & $(.87)$ & $.36 * * *$ \\
\hline 17. Religiosity (Beliefs about God) & .00 & $-.11 * *$ & $.09^{*}$ & $-.10^{*}$ & -.06 & .02 & -.07 & -.08 & $.10^{*}$ & $.14 * *$ & .03 & .03 & .02 & .07 & -.03 & $.33 * * *$ & $(.89)$ \\
\hline Mean & .31 & 4.29 & .63 & 5.19 & 4.00 & 5.90 & 3.91 & 5.07 & 4.48 & 5.39 & 5.21 & 5.21 & 5.00 & 3.77 & 4.02 & 2.63 & 3.54 \\
\hline SD (above diagonal; observed variables) & .24 & 1.83 & 1.03 & 1.45 & 1.31 & 1.32 & 1.73 & 1.24 & 1.13 & 1.26 & 1.14 & 1.26 & 1.10 & 1.43 & 1.50 & 1.57 & 1.94 \\
\hline SD (below diagonal; latent variables) & .24 & 1.83 & 1.03 & 1.30 & 1.12 & 1.17 & 1.69 & 1.00 & .98 & 1.14 & 1.22 & 1.22 & 1.01 & 1.32 & 1.51 & 1.23 & 1.90 \\
\hline
\end{tabular}

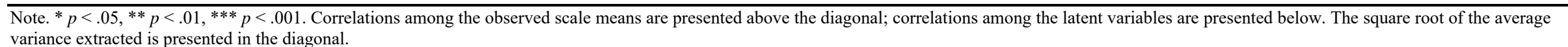


Table 3. Standardized Factor Loadings for the Measurement Model

Indicator

Loading

Attitude $($ Alpha $=.89$, Omega $=.89)$

To me, being or becoming a registered organ donor is: Unimportant/important

To me, being or becoming a registered organ donor is: Worthless/valuable

To me, being or becoming a registered organ donor is: Bad/good

Subjective Norm $($ Alpha $=.81$, Omega $=.80)$

It is expected that I will be a registered organ donor $\quad .84$

Most people who are important to me think that I should be a registered organ donor $\quad .76$

$\begin{array}{ll}\text { The people in my life whose opinions I value would approve of me being a registered organ } & .69\end{array}$ donor

Perceived Behavioral Control (Alpha $=.92$, Omega $=.92)$

Whether or not I am or become a registered organ donor is within my personal control $\quad .93$

I feel that I have complete control over whether or not I am a registered organ donor $\quad .89$

Whether or not I am or become a registered organ donor is entirely up to me

Intention to Register $($ Alpha $=.97$, Omega $=.97)$

I expect to become a registered organ donor

I intend to become a registered organ donor

I am likely to become a registered organ donor

Institutional Trust $($ Alpha $=.93$, Omega $=.93)$

The organ donation and transplant system has high integrity $\quad .95$

$\begin{array}{ll}\text { The organ donation and transplant system is honest } & .94\end{array}$

$\begin{array}{ll}\text { Organ donation and transplant staff are competent } & .88\end{array}$

When patients are eligible to donate organs, doctors can be relied upon to pronounce death $\quad .78$ correctly

Hospitals use donated organs as they are intended to be used

Trust in Others $($ Alpha $=.94$, Omega $=.94)$

I can rely on people in Australia to register as donors $\quad .95$

I can depend on other people in Australia to register as donors $\quad .93$

$\begin{array}{lr}\text { People in Australia can be trusted to register as donors } & .88\end{array}$

$\begin{array}{ll}\text { I trust that other people in Australia will register as donors } & .79\end{array}$ 
Social Inclusion $($ Alpha $=.95$, Omega $=.95)$

I feel connected with others in Australia $\quad .94$

I have a place at the table with others in Australia $\quad .92$

I feel accepted by others in Australia

I have a sense of belonging in Australia $\quad .91$

When I am with other people in Australia, I feel included .82

I have close bonds with family and friends in Australia $\quad .77$

Distributive Justice $($ Alpha $=.90$, Omega $=.91)$

I have access to hospital care I need $\quad .92$

I have fair access to hospital care $\quad .92$

I have as much access to hospitals as everyone else $\quad .77$

If I need to go to hospital, I can $\quad .77$

I feel hospital resources are shared fairly $\quad .67$

Interactional Justice $($ Alpha $=.97$, Omega $=.97)$

Hospital staff deal with me in a truthful manner $\quad .95$

Hospital staff do what's best for me $\quad .92$

Hospital staff respect my rights as a person $\quad .91$

I am treated with dignity in my encounters with hospital staff $\quad .91$

Hospital staff provide me with timely information about my care $\quad .90$

Hospital staff give me an honest explanation for the decisions they make $\quad .89$

Procedural Justice $($ Alpha $=.92$, Omega $=.92)$

Decisions about my care in hospital are based on accurate information $\quad .89$

Hospital procedures uphold ethical and moral standards $\quad .88$

Decisions about my care in hospital are unbiased $\quad .83$

I am able to query decisions about my care in hospital $\quad .83$

I am treated the same as other people in hospital $\quad .78$

I am able to express my views in hospital $\quad .77$

I am able to influence my treatment in hospital $\quad .60$

Affective Commitment (Alpha $=.94$, Omega $=.94)$

I really feel the organ donation shortage problem is my own 93

I feel emotionally attached to the cause of organ donation $\quad .92$

I am passionate about organ donation $\quad .89$

Normative Commitment $($ Alpha $=.93$, Omega $=.93)$

I feel a personal responsibility to register as a donor $\quad .93$

I feel it is morally right for me to register as a donor $\quad .89$ 
I would feel guilty if I did not register as a donor

I feel that if I am willing to accept an organ transplant, I have an obligation to register as a $\quad .73$ donor

Religiosity (Beliefs about Body) $($ Alpha $=.89$, Omega $=.90)$

Removing organs from the body just isn't right

The body should be kept whole for burial $\quad .90$

$\begin{array}{ll}\text { People who donate their organs risk displeasing God or nature } & .73\end{array}$

Religiosity (Beliefs about God) (Alpha $=.92$, Omega $=.92)$

My belief in God (or a higher power) has a great deal of influence on the way I choose to $\quad .98$ act each day

I am sure that God (or a higher power) is active in my life

Prayer is a regular part of my daily life

Note. Model fit: $\chi^{2}(\mathrm{df}=1696)=3008.204, \mathrm{p}<.001, \mathrm{CFI}=.945, \mathrm{RMSEA}=.039, \mathrm{SRMR}=.047$. Cronbach's Alpha and Coefficient Omega (Total) reliability measures (Green \& Yang, 2015) are presented above. The measurement model does not include the dichotomous items related to organ donation knowledge and experience. We did not include any cross-loadings or correlated errors within the model. 


\section{University Library}

\section{- M M N E R VA A gateway to Melbourne's research publications}

Minerva Access is the Institutional Repository of The University of Melbourne

Author/s:

Tinning, E;Bednall, TC;Bove, LL;Jordan, H

Title:

An Alternative Framing of Organ Donation Registration: The Collective Donor Behavioral Model

Date:

2021-06-01

Citation:

Tinning, E., Bednall, T. C., Bove, L. L. \& Jordan, H. (2021). An Alternative Framing of Organ Donation Registration: The Collective Donor Behavioral Model. Nonprofit and Voluntary Sector Quarterly, 50 (3), pp.531-550. https://doi.org/10.1177/0899764020968154.

Persistent Link:

http://hdl.handle.net/11343/248539 